\title{
NAVEGAÇÃO FLUVIAL A VAPOR EM SANTA CATARINA E 0 DESEMPENHO DA COMPANHIA DE NAVEGAÇÃO FLUVIAL A VAPOR ITAJAHY-BLUMENAU
}

\author{
Prof. Dr. Alcides Goularti Filho
}

Resumo: O objetivo deste texto é descrever e analisar o desempenho da navegação fluvial em Santa Catarina do último quartel do século XIX até meados do $X X$. Além de um breve panorama sobre a navegação fluvial brasileira, o texto destaca a navegação no Rio Itajaí-Açu, por meio da Companhia de Navegação Fluvial a Vapor Itajahy-Blumenau (1878-1954). No período analisado, Santa Catarina apresentava uma especialização regional e uma fragmentação econômica, que refletia nas vias de comunicação e nos meios de transporte, gerando um sistema desarticulado, que, de certa forma, atrasou a integração regional catarinense. A Companhia de Navegação Fluvial a Vapor Itajahy-Blumenau foi fundada em 1878 e fazia o trajeto entre a colônia de Blumenau e o porto de Itajaí. Em 1909, a Companhia foi incorporada pela Estrada de Ferro Santa Catarina, que realizava o transporte conjugado das colônias do interior (via férrea) ao litoral (via fluvial). Em 1919, a Companhia de Navegação e a Estrada de Ferro foram encampadas pela União e repassadas ao governo estadual. Nos anos de 1930, ambas passaram a apresentar resultados deficitários, e a navegação foi sendo aos poucos menos utilizada e com a extensão da linha ferroviária de Blumenau a Itajaí, inaugurada em 1954, a navegação foi desativada por completo. Mesmo sendo deficitária, a navegação pelo Rio Itajaí-Açú foi fundamental para integrar Blumenau a outras praças comerciais mais importantes.

Palavras-chave: Transporte Fluvial; Navegação; Comunicações; Integração Econômica; Santa Catarina

Abstract: The objective of this text is to analyze the performance of the fluvial
navigation in the state of Santa Catarina in the last quarter of the XIXth century
until half of the XXth. After a brief panorama on the Brazilian fluvial navigation,
the text pay special attention to the navigation in the Itajaí-Açu River by the
"Companhia de Navegação Fluvial a Vapor Itajahy-Blumenau" (1878-1954). In
the analyzed period, Santa Catarina presented a regional specialization and an

' Doutor em Economia pela Unicamp. Professor do Curso de Economia da Unesc. E-mail para contato: alcides@unesc.net. 
economic spalling that reflected in the communication and transportation routes, generating a disarticulated system that, in a certain form, delayed the state's regional integration. The "Companhia de Navegação Fluvial a Vapor ItajahyBlumenau" was established in 1878 and navigated between the colony of Blumenau and the port of Itajaí. In 1909, the Company was incorporated by the "Estrada de Ferro Santa Catarina” who did the conjugated transportation from the colonies in the hinterland (by railway) to the coast (by river). In 1919, the navigation company and the railroad had been expropriated by the Federal Government and passed to the state government. In the 1930's both had started to present a business loss and the navigation started to loose its significance. After the railway line extension from Itajaí to Blumenau, inaugurated in 1954, the navigation was completely deactivated. Even with its budget deficits, the navigation throughout the ItajaíAçú River was fundamental to the Blumenau integration into a larger and more important commercial net.

Key-Words: Fluvial Transportation; Navigation; Communication; Economy Integration; Santa Catarina

\section{INTRODUÇÃO}

A formação econômica de Santa Catarina é marcada por algumas características singulares na sua história e na sua geografia. Do ponto de vista do relevo, o território catarinense está dividido entre planícies, patamares, serras e planaltos, ou seja, com apenas 95 mil km², Santa Catarina tem um relevo bem irregular. Talvez pudéssemos dividir em duas grandes áreas: a) o planalto (serrano, norte, meio oeste e oeste); b) a planície e as serras ao leste catarinense (sul, litoral, vale do Itajaí e norte). Estas duas áreas são separadas pela Serra Geral (do extremo sul ao baixo vale do Itajaí) e pelos patamares do Alto Rio Itajaí, além da Serra do Mar no norte do estado. Podemos afirmar que até o início do século XX, estas serras eram as barreiras naturais que dificultavam a integração econômica e demográfica em Santa Catarina. O litoral já era ocupado desde o século XVII, onde foram fundadas as freguesias de São Francisco (norte), Desterro, atual Florianópolis, (leste) e Laguna (sul). A ocupação rarefeita do planalto serrano se deu em função dos caminhos das tropas que ligavam as fazendas gaúchas com a feira de Sorocaba. A região estava mais em contato com São Paulo e Rio Grande do Sul, do que com o litoral catarinense. As colônias de imigrantes formadas no final do século XIX, estavam todas localizadas no sul, vale do Itajaí e norte. No final do século XIX e início do XX, o contato comercial entre o planalto, as colônias e o litoral era muito esporádico, feito por tropeiros que desciam a serra em direção a Laguna ou Desterro. E a ocupação mais efetiva do 
oeste catarinense ocorreu somente após-1915 pelos colonos gaúchos teuto e ítalobrasileiros, que faziam parte do incipiente movimento da expansão das fronteiras agrícolas em direção ao Centro-Oeste brasileiro. O movimento migratório mais expressivo era do noroeste gaúcho para o oeste catarinense, e não do litoral catarinense para o oeste. ${ }^{2}$

No último quartel do século XIX, começaram a se formar as especializações regionais catarinenses distribuídas em todo o território de forma fragmentada. No sul, açorianos e colonos produziam alimentos e derivados de animais comercializando com várias praças urbanas via porto de Laguna. A descoberta do carvão e a entrada em operação da Estrada de Ferro Dona Tereza Cristina (EFDTC), em 1884, já esboçavam os rumos da economia local. No vale do Itajaí, as colônias estavam integradas com Blumenau que escoava a produção de alimentos, madeira, derivados de animais e têxteis pelo porto de Itajaí, via Rio Itajaí-Açú. No norte, a extração da erva-mate do Paraná expandiu-se para Santa Catarina onde se formou um complexo ervateiro integrando Estrada Dona Francisca, navegação fluvial nos rios Iguaçu e Negro, beneficiamento, comércio exportador e porto de São Francisco do Sul. No planalto serrano, que era cortado pelo caminho que seguia para Sorocaba, predominava a pecuária. No oeste, onde também havia a presença de um caminho que seguia até Castro (PR), ainda predominavam as grandes fazendas e havia disponível uma extensa reserva de araucária.

Este quadro foi se alterando aos poucos durante a primeira metade do século $\mathrm{XX}$. Houve um redirecionamento de alguns setores, o aprofundamento e desdobramentos de outros. No sul, formou-se o complexo carbonífero com a expansão da EFDTC, a construção de usinas de beneficiamento de carvão e os melhoramentos no porto de Imbituba. No vale do Itajaí, a indústria têxtil se consolidou integrando-se do mercado nacional. Joinville tornou-se o grande centro industrial catarinense com a presença da indústria metal-mecânica. No planalto serrano, a pecuária extensiva continuou se expandindo, além de se especializar nas atividades madeireiras. E no oeste, após esgotar as reservas de araucária, já se apresentava característica de um complexo agroindustrial de carnes em formação.

$\mathrm{O}$ que podemos perceber é que até a metade do século XX, a economia catarinense apresentava uma especialização regional e uma fragmentação econômica. Esta situação reverteu-se somente nas décadas seguintes com a diversificação e integração comercial e produtiva da economia catarinense comandada pelas grandes indústrias e pelo Estado.

Esta especialização fragmentada gerou um sistema de transporte fragmentado, voltado para as especializações regionais. No meio-oeste, a Estrada de Ferro São Paulo-Rio Grande (EFSPRG) atendia às demandas da indústria madeireira e da pequena indústria de alimentos. No norte e planalto norte o Ramal Ferroviário Porto 
União-São Francisco do Sul, a Estrada Dona Francisca e a navegação fluvial davam suporte às atividades ervateiras e madeireiras. No vale do Itajaí, a Estrada de Ferro Santa Catarina (EFSC) e a Companhia de Navegação Fluvial a Vapor Itajahy-Blumenau atendiam às demandas da indústria madeireira, da agricultura local e da pequena produção mercantil. No sul, a EFDTC e o Canal de Navegação Fluvial Laguna-Jaguaruna atendiam às atividades carboníferas, o comércio e à agricultura local. Ou seja, o sistema de transporte catarinense funcionava de forma desarticulada atendendo à regiões específicas. Esta situação concreta foi um dos elementos determinantes que atrasou a integração regional catarinense. ${ }^{3}$

O objetivo deste texto é descrever e analisar o desempenho da navegação fluvial em Santa Catarina do último quartel do século XIX até meados do XX destacando a navegação fluvial no Rio Itajaí-Açú, com ênfase na Companhia de Navegação Fluvial a Vapor Itajahy-Blumenau. Além desta breve introdução e das considerações finais, o texto está dividido em três tópicos: inicialmente, será feito uma discussão mais geral sobre a navegação fluvial no Brasil apontando a falta de um sistema nacional integrado; em seguida, o texto traz uma breve introdução sobre a hidrografia catarinense e aponta as diversas localidades mais próximas ao litoral onde se desenvolveu a pequena navegação fluvial e lacustre; e por último, destacamos o desempenho da Companhia de Navegação Fluvial a Vapor Itajahy-Blumenau de 1878 a 1954, que fazia o percurso de 72,3 quilômetros entre Blumenau e o porto de Itajaí e que foi a única companhia de navegação fluvial em Santa Catarina.

A partir deste objetivo será discutido o sistema de transporte fragmentado dentro de uma economia especializada. Nesta economia, como se dá a combinação das várias modalidades de transportes, focando no sistema de navegação fluvial apresentado o desempenho da Companhia de Navegação Fluvial a Vapor Itajahy-Blumenau discutindo as dificuldades materiais, os déficits financeiros e a concorrência.

\section{NAVEGAÇÃO FLUVIAL NO BRASIL}

Durante a colonização, as monções, juntamente com as entradas e as bandeiras, alargaram as fronteiras do Brasil por meio de canoas que desciam os rios paulistas, que integravam com os do Paraná e do Mato Grosso. Grandes expedições formadas por vicentistas aventureiros desciam os caudalosos rios em canoas à procura de pedras preciosas e índios (HOLANDA, 1994). Este movimento das monções foi responsável pela "descoberta” dos grandes rios navegáveis no centro-sul da colônia. O desenvolvimento dos meios de transportes acompanhava o movimento de povoamento do litoral para o interior, espalhando-se para os diversos núcleos afastados do mar e desintegrados entre si. ${ }^{4}$

O território brasileiro é formado pelas seguintes grandes bacias hidrográficas: Amazonas, Atlântico Sul (que envolve os trechos, Norte, Nordeste, Leste e 
Sudeste), Tocantins, São Francisco e Prata (Paraná e Uruguai). Os grandes rios navegáveis de integração macrorregional são o Amazonas (e grande parte dos afluentes), Araguaia, Tocantins, Parnaíba, Paraná e São Francisco. Além destes, há uma série de rios com larga extensão navegável, mas são de segunda ordem de grandeza e estão circunscritos a um único Estado, como é o caso dos rios Jacuí, Ibicuí e Taquari no Rio Grande do Sul; do Rio Tietê em São Paulo. No planalto, devido aos fortes declives, os rios são mais utilizados para produção de energia, já na planície, são mais utilizados para a navegação.

Em 1869, o engenheiro geógrafo Eduardo José de Moraes publicou um minucioso estudo sobre a navegação fluvial no Brasil. Ele dividiu o sistema hidrográfico brasileiro em quatro grandes junções: bacia leste (São Francisco/Rio Grande/SP com o mar), bacia oeste (Amazonas com o Prata), bacia centro (Araguaia e Tocantins) e bacias de segunda ordem. A proposta de Moraes era promover uma integração entre o Rio Tapajós, afluente do Amazonas, com o Rio Paraguai, por meio de um canal de navegação e outro canal que deveria ligar o Rio Grande (em São Paulo) ao Rio São Francisco. O Rio São Francisco seria integrado com o Rio Parnaíba também por meio de um canal entre os rios Preto e Gurguéia. Segundo Moraes:

O Brasil de 1869 é ainda o Brasil colônia, que se reduzia ao simples litoral do Atlântico ou a sua fronteira marítima. Para o desenvolvimento de sua prosperidade comercial recursos estratégicos e o seu progressivo engrandecimento, cumpre que se cuide seriamente em obter-se uma navegação interior, lançando-se desde já os fundamentos da rede geral que no futuro facilitará a comunicação da capital do Império com os mais remotos pontos do seu território. ${ }^{5}$

O "plano” de Moraes previa a construção de alguns canais de navegação, sem muitos ônus para o Estado, que poderia integrar o interior do território do Império ao litoral, navegando pelos rios. Ele acreditava que o desenvolvimento dos transportes promoveria a "prosperidade” de várias regiões brasileiras. Ou seja, mesmo numa região que não houvesse uma atividade produtiva com um fluxo intenso de mercadoria, com a chegada do navio estimularia o seu "progresso".

Apesar de uma ampla bacia hidrográfica com longos trechos navegáveis, a navegação fluvial a vapor brasileira desenvolveu-se muito pouco, principalmente quando comparamos com a dos EUA. Até o final do Império não havia um sistema de transporte no interior que fosse integrado, combinando as diversas vias de comunicação. No interior havia os velhos caminhos, moldados pelos bandeirantes e tropeiros. Já as estradas de ferro, construídas durante o Segundo Reinado e a Primeira República, funcionavam de forma desarticulada sem uma lógica integradora. Ambos deveriam combinar com a navegação fluvial para integrar-se com os portos. 
A primeira iniciativa institucional elaborada durante o Império para estimular a navegação fluvial foi a Lei de 29 de agosto de 1828 que estabeleceu regras para a construção de obras púbicas que tivessem por objetivo "a navegação de rios, abertura de canais, edificação de estradas, pontes, calçadas ou aquedutos”. ${ }^{6}$ Em 1833, o Decreto 60 de 8 de outubro autorizou o governo a contratar companhias nacionais ou estrangeiras para o uso exclusivo da "navegação por barcos de vapor nos rios e baias do Império". ${ }^{7}$ Este Decreto impulsionou a constituição de companhias de navegação marítima que passaram a cobrir o litoral brasileiro, com destaque para a Companhia Brasileira de Paquetes a Vapor. Finalmente, o Decreto 632 de 18 de setembro de 1851 deu um grande impulso à navegação marítima e fluvial no Brasil criando garantias para as companhias que transportassem as malas postais subvenção anual de 70 contos de réis nos primeiros 10 anos e 40 contos de réis nos anos seguintes, além de garantia de juros de $8 \%$ sobre o capital empregado. ${ }^{8}$

A pioneira na navegação fluvial a vapor foi a Companhia de Navegação do Rio Doce, que navegava nos rios Doce e Jequitinhonha, mais tarde foi abandonada devido aos problemas de assoreamento nos rios. ${ }^{9} \mathrm{Na}$ época, o maior empreendimento na área foi a navegação fluvial a vapor na bacia do Amazonas e seus afluentes, iniciada em 1854 pela Companhia de Comércio e Navegação do Amazonas, de propriedade do Barão de Mauá. ${ }^{10}$

Além dos caminhos e da navegação fluvial, a partir de meados do século XIX, as vias de comunicação no Brasil ganharam um novo e grande impulso modernizante: as ferrovias. Apesar de algumas tentativas frustradas de estimular a expansão ferroviária durante o período regencial, foi com a expansão da economia cafeeira, que as ferrovias começaram definitivamente a ser construídas no Brasil. Em 1859, a malha ferroviária brasileira era de 109 km, em 1869 já atingia 713 km e em 18792.895 km. É o início do grande boom ferroviário brasileiro que vai se estender até os anos de 1920, quando em 1929 a malha ferroviária já era de $32.000 \mathrm{~km}$ (SILVA, 1976).

Entre os anos de 1840 e 1880 a navegação fluvial e marítima a vapor no Brasil viveu um período de prosperidade com o surgimento de várias companhias e com a edição de leis e decretos que beneficiaram o setor. No final do século e nos primeiros anos da República começamos a assistir a um movimento de centralização das atividades da navegação com a criação, em 1890, do Lloyd Brasileiro, uma grande empresa estatal de navegação transoceânica, e, em 1907, com a criação da Inspetoria Federal de Navegação, um órgão do Ministério da Viação e Obras Públicas encarregado de regular e fiscalizar a navegação. Concomitantemente, assistimos nesse período ao florescer da era ferroviária no Brasil, que suplantou a navegação a vapor marítima e fluvial relegando-a a um plano inferior 
na lista de prioridades do governo federal. Com a industrialização pós-1930, a navegação fluvial já não atendia mais às crescentes demandas internas do novo padrão de acumulação que priorizava o mercado interno, portanto a integração nacional. Como o sistema fluvial brasileiro não era integrado, dificultando a navegação interior de longa distância, e as ferrovias atendiam principalmente às regiões exportadoras, as rodovias surgiram como o principal elemento integrador e distribuidor da produção capitalista em todo o território nacional.

\section{NAVEGAÇÃO FLUVIAL EM SANTA CATARINA E NA DIVISA COM O PARANÁ}

A navegação fluvial em Santa Catarina se fez presente em diversos pontos da vertente do Atlântico (Araranguá, Tubarão, Tijucas e Itapocu), porém eram iniciativas individuais de canoeiros e pequenos comerciantes locais que utilizavam pequenos barcos como meio de transporte para ligar vilas e comunidades. Entre Joinville e o porto de São Francisco do Sul havia navegação fluvial no Rio Cachoeira e na Lagoa de Saguaçú. No sul, havia a navegação nas lagoas de Imaruí e de Santo Antônio, ambas em Laguna. Nesta mesma região, também havia o canal de navegação que ligava as cidades de Jaguaruna e Laguna, passando pelos rios Sangão, da Madre e Tubarão, numa extensão de 31 km. Mais ao sul havia a navegação entre Araranguá e Torres, via Rio Sangradouro e lagoas do Caverá e Sombrio, chegando até o Rio Mampituba, numa extensão de 45 km.

Porém, foi apenas no Rio Itajaí-Açu que surgiu uma companhia capitalista de navegação fluvial a vapor organizada e com fluxo constante de pessoas e mercadorias. Na vertente do Atlântico, em Santa Catarina está situado o ItajaíAçu, que nasce e desemboca no território catarinense e forma a maior bacia hidrográfica dentro do estado, abrangendo uma área de $15.500 \mathrm{~km}^{2}$.

A navegação fluvial em Santa Catarina foi uma atividade pouco desenvolvida, principalmente se compararmos com outros estados brasileiros que têm uma rede hidrográfica maior e uma planície com menos declive. Os três estados do Sul têm as mesmas bacias hidrográficas: a bacia do Atlântico Sul (trecho sudeste) e a bacia do Prata, com dois grandes afluentes, o Rio Uruguai e o Rio Paraná. As duas vertentes em Santa Catarina, Atlântica e Interior, estão separadas pela Serra Geral. Os rios navegáveis estão situados na vertente do Atlântico, uma vez que no planalto há um longo declive que se estende até a fronteira com a Argentina. As duas bacias que recebem as águas da vertente do Interior são a do Rio Uruguai e a do Rio Iguaçu.

No estado do Paraná, os rios são mais favoráveis para a geração de energia elétrica do que para a navegação. O maior rio navegável é o Rio Paraná que desde a sua nascente, no Rio Paranaíba, até a sua foz (no Rio do Prata) são 4.965 km, sendo que 3.367 km são plenamente navegáveis. Os outros rios são o Tibají, numa extensão 
navegável de apenas 78 km e o Ivaí, com 140 km de navegabilidade. A navegação nestes rios sempre foi explorada por companhias paulistas ou argentinas.

Duas atividades extrativistas marcaram a economia paranaense na segunda metade do século XIX, a erva-mate e a madeira (araucária). A floresta da araucária predominava em grande parte do sul e sudoeste e no centro do território paranaense e a erva-mate, junto com a araucária, ao longo da divisa com Santa Catarina. Ambas as atividades foram responsáveis por movimentar grande parte da economia do Paraná, orientando a ocupação demográfica, a construção de estradas de rodagem, de ferrovias e a navegação fluvial. A Estrada da Graciosa, da Itapuava e do Arraial, que desciam a Serra do Mar até os portos no litoral foram abertas com o intuito de escoar a produção de erva-mate. ${ }^{11} \mathrm{O}$ mesmo ocorreu com a abertura da Estrada Dona Francisca, em Santa Catarina, entre Joinville e Rio Negro, que além de escoar a produção de erva-mate, levando-a até ao porto de São Francisco do Sul, também beneficiava as novas colônias de imigrantes. ${ }^{12}$ Os melhoramentos feitos nos portos de Paranaguá, Antonina e São Francisco, estavam todos relacionados ao movimento de carga comandado pela erva-mate e pela madeira. A construção da imponente Estrada Ferro do Paraná (Curitiba-Paranaguá) e do ramal Porto União-São Francisco da Estrada de Ferro São Paulo-Rio Grande, também está associada à forte expansão das atividades extrativistas no Paraná e em Santa Catarina.

O Rio Iguaçu, com $1.320 \mathrm{~km}$, tem uma extensão navegável de $360 \mathrm{~km}$ ao longo do Segundo Planalto, desde a cidade de Porto Amazonas (PR) até Porto União (SC) e União da Vitória (PR). A navegação no Rio Iguaçu já era praticada desde o período colonial, mas efetivamente a navegação a vapor iniciou em 1882. A partir desta data surgiram várias outras companhias que desciam o Rio Iguaçu e seguiam pelo Rio Negro até a cidade de Mafra. Em 1915, o governo paranaense encampou várias empresas de navegação que recebiam subvenções, num total de 10 barcos, e formou a Lloyd Paranaense. ${ }^{13}$ Mesmo assim, novas companhias privadas continuaram a ser formadas. Ao todo, nos anos de 1920, trafegavam pelo Rio Iguaçu 28 navios de 12 companhias de navegação. ${ }^{14}$ Em 1953, a Lloyd Paranaense, que já atuava em outros rios paranaenses, foi liquidada e suas atividades foram encerradas, pondo fim a um longo período de navegação fluvial na divisa do Paraná com Santa Catarina. ${ }^{15}$

\section{COMPANHIA DE NAVEGAÇÃO FLUVIAL A VAPOR ITAJAHY- BLUMENAU}

\subsection{Uma companhia privada}

A vinda de imigrantes para Santa Catarina na segunda metade do século XIX, deu-se em dois momentos. O primeiro, com a fundação das colônias de 
Blumenau, em 1850, e de Joinville, em 1851; o segundo, no último quartel do século, com a fundação de várias colônias no Vale do Itajaí, planalto norte e sul de Santa Catarina. No Vale do Itajaí podemos destacar três núcleos importantes: Itajaí, Blumenau e Brusque. Itajaí era uma vila portuária habitada por pescadores; Brusque e Blumenau duas colônias de imigrantes alemães que rapidamente se desenvolveram, sobretudo a partir da chegada da segunda leva de imigrantes. Blumenau foi povoada nas margens do Rio Itajaí-Açu, onde desenvolveu-se o sistema colônia-venda que tinha como base a pequena produção mercantil. A acumulação era conduzida pelas atividades agrícolas e manufatureiras, como produção de derivados de suínos, laticínios, cereais, madeira e produtos têxteis. O excedente era comercializado com toda a hinterland e com Florianópolis, além de ser exportado para o Rio de Janeiro e São Paulo. Era condição necessária para a prosperidade dos negócios e para a fixação dos colonos que a produção fosse escoada até ao porto de Itajaí. ${ }^{16}$

A primeira tentativa de constituir uma companhia de navegação a vapor entre Blumenau e Florianópolis, passando por Itajaí, Porto Belo e Tijucas foi feita por Fernando Ebert, em 1861. O projeto chegou a ser debatido na Assembléia Provincial, mas foi abortado após a intervenção de Hermann Blumenau, Diretor da Colônia, que alegavam insuficiência financeira para tal empreendimento. ${ }^{17} \mathrm{Na}$ era da navegação a vapor (fluvial e marítima), de 1840 a 1880, tentar formar uma companhia de navegação em Blumenau, estava dentro das condições materiais disponíveis e da idéia dominante da época. Como não havia acumulação de capital suficiente na região para construir uma ferrovia, a fundação de uma companhia de navegação seria a solução mais viável.

No dia 17 de maio de 1872, a Assembléia Legislativa Provincial de Santa Catarina baixou um decreto que autorizava o Presidente de Província a contratar os serviços de uma companhia de navegação por meio de lancha a vapor entre as vilas de Itajaí, Blumenau e Brusque. Tais lanchas deveriam ser apropriadas para os rios Itajaí-Açu e Mirim. O prazo para abertura da companhia era de um ano, e teria subvenção do governo provincial apenas se o tesouro tivesse recursos disponíveis. A companhia poderia ser organizada dentro ou fora do Império e o privilégio seria garantido por um período de 30 anos. ${ }^{18}$

Como não houve nenhuma resposta imediata para resolver o problema do transporte entre Blumenau e Itajaí, o Decreto 5.811 de 03 de setembro de 1874 aprovou o contrato celebrado entre a Companhia Nacional de Navegação a Vapor e a Diretoria Geral dos Correios que obrigava a Companhia a fazer três viagens mensais entre a província de Santa Catarina e a Corte, subindo o Rio Itajaí-Açu, atracando no porto de São Francisco indo até a Lagoa de Saguaçu, além de fazer pequenas paradas nos portos de Tijucas, Porto Belo e Itajaí. ${ }^{19}$ 
Era empregado na realização das viagens o vapor São Lourenço, que já era de propriedade da Companhia Nacional, sendo tripulado por 14 pessoas, com capacidade para 91,14 toneladas métricas, força de 40 cavalos, calado de 1,37 metros e podia acomodar até 54 passageiros. Para tanto, a Companhia receberia uma subvenção mensal de 2,5 contos de réis por mês. Como havia dificuldades para o navio São Lourenço chegar até Blumenau, dado o baixo calado Rio Itajaí-Açu, o ponto final era a localidade de Gaspar. ${ }^{20}$

Mesmo com a chegada do vapor São Lourenço, o problema ainda persistia, pois entre Blumenau e Gaspar o trajeto era feito a cavalo margeando o rio ou em pequenas embarcações a remo. Como resposta a esta situação crítica, no dia 30 de abril de 1877, circulou no jornal Blumenauer Zeitung um abaixo-assinado elaborado por pequenos capitalistas locais, solicitando a presença de interessados em fundar uma companhia de navegação fluvial em Blumenau para comparecerem na assembléia geral que seria realizada no dia 2 de maio no Clube dos Atiradores. ${ }^{21}$ No ano seguinte, em 20 de maio de 1878, foi fundada a Companhia de Navegação Fluvial a Vapor Itajahy-Blumenau, com um capital de 30:000\$000 dividido em 300 ações de $100 \$ 000$ cada e prazo de duração de 20 anos. ${ }^{22} \mathrm{O}$ quadro de sócios fundadores da Companhia era o seguinte:

Quadro 1: Sócios fundadores da Companhia de Navegação Fluvial a Vapor

\begin{tabular}{llll}
\hline Nome & Nacionalidade & Profissão & Cidade \\
\hline Meyer \& Spierling & Alemã & Negociante & Blumenau \\
Luiz Sachtleben & Brasileira & Negociante & Blumenau \\
Fernando Schrader & Brasileira & Negociante & Blumenau \\
Hermman Blumenau & Alemã & Empregado & Blumenau \\
H. Greoesmuhl & Alemã & Dono de engenho & Blumenau \\
Henrique Probst & Alemã & Negociante & Blumenau \\
Guilherme Friedenreith & Brasileira & Fabricante & Blumenau \\
João Soheep & Brasileira & Fabricante & Blumenau \\
Pedro Hartmann & Brasileira & Padeiro & Blumenau \\
Dr. Valloton & Suíço & Médico & Blumenau \\
João Ehmke & Brasileira & Lavrador & Blumenau \\
H. Wendeburg & Brasileira & Empregado & Blumenau \\
João Marques da Silva & Brasileira & Negociante & Cidade de Itajaí \\
Guilherme Asseburg & Brasileira & Negociante & Cidade de Itajaí \\
Nicolau Malburg & Brasileira & Negociante & Cidade de Itajaí \\
Rudolfo Herbst & Brasileira & Negociante & Barra do Itajaí \\
Fernando Hachradt & Brasileira & Negociante & Desterro \\
Bade Kirbach \& Comp & Brasileira & Negociante & Desterro \\
\hline
\end{tabular}

Fonte: Coleção das Leis do Império do Brasil de 1878. Rio de Janeiro: Tipografia Nacional, 1879, p. 467-468. 
O primeiro vapor da Companhia foi o Progresso, construído na Alemanha com 22 metros de comprimento e 3,34 metros de largura, que passou a navegar no Rio Itajaí-Açu em 1879. A Itajahy-Blumenau atendia as localidades situadas ao longo da margem do rio, como Gaspar e Ilhota, fazendo três viagens semanais até Itajaí num percurso de 72,3 km. A chegada de novos imigrantes, a colonização do interior de Blumenau e a expansão das atividades econômicas exigiram novos investimentos na Itajahy-Blumenau, que encomendou um novo vapor: o Blumenau. Também construído na Alemanha, o vapor Blumenau media 28 metros de comprimento e 4,40 metros de largura, começando a operar em junho de 1895.

A Itajahy-Blumenau chegou em 1900 com a seguinte frota: os navios Blumenau, Progresso e Jan e as lanchas Coral e Caninana. Além de um barracão em Blumenau e armazém e estaleiro em Itajaí. ${ }^{23}$ Os balanços publicados no Blumenauer Zeitung entre 1895 e 1905 mostram que a Itajahy-Blumenau operava com bom equilíbrio financeiro, situação que se reverteu nas décadas seguintes. Com a entrada em operação da Estrada de Ferro Santa Catarina (EFSC), em 1909, o tráfego entre as colônias do interior de Blumenau com o porto de Itajaí passou a ser conjugado com a ferrovia. A EFSC foi construída com capital alemão, num percurso de apenas 69,7 km entre Blumenau e Hansa (Ibirama). Neste mesmo ano, dois terços das ações da Itajahy-Blumenau foi adquirido pela Companhia EFSC, que em seguida passou a atuar de forma conjugada com a ferrovia. ${ }^{24}$

A EFSC proporcionou um aumento no fluxo de mercadorias transportadas pela navegação fluvial, pois havia a conjugação das duas modalidades. As mercadorias que vinham do interior do vale do Itajaí eram transportadas pela ferrovia até Blumenau, que seguia viagem pelo rio até o porto de Itajaí, com destaque para madeira, cereais, alimentos e fécula de mandioca. Ambas as modalidades possibilitavam escoar a produção do vale do Itajaí colocando-a em vários mercados, inclusive em São Paulo e Rio de Janeiro.

\subsection{INTERVENÇÃO ESTATAL}

Com a deflagração da Primeira Guerra Mundial o governo brasileiro declarou guerra à Alemanha e todos os bens e direitos pertencentes a proprietários alemães no Brasil foram suspensos ou encampados. O Decreto 12.907 de 6 de março de 1918 declarou sem efeito o contrato celebrado entre o Governo da União e a Companhia Estrada de Ferro Santa Catarina, e o Decreto 13.539 de 9 de abril de 1919 requisitou todo o material da Companhia de Navegação Fluvial a Vapor Itajahy-Blumenau, para incorporá-lo à Estrada de Ferro Santa Catarina. O preâmbulo do Decreto esclarecia os motivos da encampação:

- Considerando que é necessária como medida econômica e de interesse nacional, incorporar esse material na referida es- 
trada, para que realiza o serviço de navegação que tem estado a cargo da mencionada companhia, e possa em melhores condições executar aquele os trabalhos de construção dos seus prolongamentos;

- Considerando que da lista nominativa dos acionistas da companhia, conforme o cadastro organizado em cumprimento da lei n. 3.303 de 16 de novembro de 1917, se verificar ser a mesma companhia constituída por 1.000 ações das quais 927 pertencem á antiga Companhia Estrada de Ferro Santa Catharina, e são, por conseguinte de propriedade inimiga, ex-vi do art. $6^{\circ}$ da citada lei;

- Considerando que, sendo pessoa inimiga a Companhia de Navegação Fluvial a vapor Itajahy-Blumenau, não pode o Governo com ela contratar, ainda que tivesse essa companhia personalidade jurídica, o que não tem, por não haver satisfeito os requisitos legais para o seu funcionamento na Republica (Decreto 13.539 de 9 de abril de 1919)

Em seguida, o Decreto 15.152 de 2 de dezembro de 1921 autorizou a celebração de contrato de arrendamento e de construção da Estrada de Ferro Santa Catarina com o Estado de Santa Catarina, ficando o governo estadual responsável pela administração da ferrovia e da seção fluvial. Ou seja, a partir desta data, a Companhia de Navegação Fluvial a Vapor Itajahy-Blumenau tornou-se uma estatal denominada Seção Fluvial da Estrada de Ferro Santa Catarina. E é justamente a partir desta data que a navegação começou a sofrer concorrência com as estradas e com os caminhões, além da concorrência que já vinha sofrendo com a presença de outras companhias privadas de navegação em Blumenau. E para completar o quadro precário da Itajahy-Blumenau, seus equipamentos estavam rapidamente se deteriorando em estado crítico. ${ }^{25}$

Constantemente o vapor Blumenau e o rebocador Santa Catarina, além das diversas lanchas, passavam por reparos no estaleiro da Companhia em Itajaí. O rebocador Santa Catarina era o mais dispendioso da frota, tanto que o presidente da EFSC solicitou que o mesmo fosse vendido para reduzir as despesas de reparos. No quadro abaixo podemos acompanhar a data de fabricação, comprimento e capacidade de carga dos materiais flutuantes da Seção Fluvial da EFSC, no ano de 1922. Como se percebe, eram materiais relativamente velhos e não havia uma renovação da frota. Nesta época já estavam fora de circulação as lanchas Caninana, Coral e o navio Jan. 
Quadro 2: Características dos materiais flutuantes da Seção Fluvial da Estrada de Ferro Santa Catarina em 1922.

\begin{tabular}{lccc}
\hline Nome da embarcação & Ano de fabricação & Comprimento & Toneladas registradas \\
\hline Lancha Progresso (antigo vapor) & 1879 & 25,4 & 20,0 \\
Vapor Blumenau & 1897 & 28,0 & 30,0 \\
Lancha Itoupava & 1900 & 14,8 & 15,0 \\
Lancha Itajaí & 1907 & 26,0 & 96,0 \\
Lancha Gaspar & 1907 & 20,0 & 22,0 \\
Lancha Stephanie & 1908 & 26,0 & 80,0 \\
Rebocador Santa Catarina & 1908 & 16,0 & 30,0 \\
Lancha Altona & 1917 & 22,0 & 20,0 \\
Lancha Boa Esperança & 1922 & 23,0 & \\
\hline
\end{tabular}

Fonte: Relatório apresentado ao Governador de Santa Catarina pelo Diretor Joaquim José de Souza Breves Filho no ano de 1922. Blumenau: Tipografia Baumgarten, 1922, p. 49-50.

No Relatório da EFSC, o diretor da Companhia, José de Souza Breves Filho, fez a seguinte observação sobre as condições materiais dos equipamentos da Seção Fluvial:

O material fluvial não está aparelhado para tirar a vantagem que poderia da concorrência que lhe fazem outras empresas. Embarcações em geral muito idosas, quase todas exigem grandes e dispendiosas reparações, que vão sendo executadas com vagar, a medida que vão permitindo as finanças da Estrada. ${ }^{26}$

O desgaste dos equipamentos a partir dos anos de 1920 também estava associado ao transporte dos materiais permanentes e rodantes destinados aos prolongamentos da EFSC em direção ao oeste. No Relatório de 1928, temos a seguinte reclamação do diretor sobre a Seção Fluvial:

Os resultados do tráfego corroboram a situação que vem se observando de um aumento das receitas da via férrea, enquanto que a Seção Fluvial, a partir de 1926, vem caindo de ano para ano. Este fato é conseqüência, principalmente, da capacidade de transportes cada vez menor que vem apresentando essa Seção, o que não é estranhável, constituída como está por velhas embarcações, que têm exigido constantes e grandes reparações. ${ }^{27}$

Os maiores gastos com reparações estavam concentrados no rebocador Santa Catarina, pois o seu calado não se adaptava à navegação fluvial no Rio Itajaí-Açu. Em 1930, o rebocador contribuiu com 50,2\% do déficit total da Seção Fluvial. ${ }^{28}$ 
A partir dos dados disponíveis do desempenho da Seção Fluvial de 1912 a 1951 podemos fazer a seguinte análise. O vapor Blumenau e o rebocador Santa Catarina faziam em média 160 viagens por ano, transportando nas lanchas em torno de 13.000 toneladas. O transporte de passageiros, ao longo do período, foi sofrendo quedas constantes, passando de 7.566 passageiros em 1920 para 1.553 em 1928. Em 1937, foram transportados 2.230 passageiros em 1938 caiu para 488 e nos anos seguintes continuou caindo até este serviço ser desativado em 1944. Com relação aos resultados financeiros, dos 29 anos analisados, com dados disponíveis, 23 apresentaram déficits. A partir de 1935, os déficits foram constantes, e, somados aos déficits da Seção Férrea, estavam inviabilizando a Estrada de Ferro Santa Catarina. Para o governo estadual, a única solução seria prolongar a ferrovia até o porto de Itajaí e prolongar para oeste ao encontro da antiga Estrada de Ferro São Paulo-Rio Grande. A ligação férrea entre Blumenau e Itajaí desativaria a Seção Fluvial eliminando os déficits.

No Relatório de 1937, o diretor da EFSC, Francisco de Abreu e Lima Júnior afirmou que a Seção Fluvial continuava sendo o "peso morto da Estrada”. ${ }^{29}$ Para o governo estadual, enquanto não eliminasse a Seção Fluvial não mudaria a situação econômica que "afligia a EFSC". ${ }^{30}$ Para agravar ainda mais a situação, a própria EFSC em 1936, a exemplo de outras companhias ferroviárias brasileiras, montou uma Seção Rodoviária com dois caminhões e dois ônibus, para concorrer com as empresas de transportes que estavam surgindo na região. Se por um lado a Seção Rodoviária dinamizou a EFSC concorrendo com os caminhões que desciam de Lages carregados de madeira para o porto, por outro lado criou uma concorrência interna prejudicando ainda mais a Seção Fluvial, que já vinha enfrentando concorrência com outras empresas de navegação em Blumenau desde os anos de 1920.

Com o prolongamento dos trilhos da EFSC de Blumenau a Itajaí, cuja construção foi retomada em 1936 e inaugurada apenas em dezembro de 1954, a Seção Fluvial continuou operando até essa data, mesmo apresentando déficits constantes. Parar os serviços fluviais prejudicaria o escoamento da produção de Blumenau e da região, o que, do ponto de vista político, não seria conveniente para o governo estadual. Blumenau neste momento passava por uma forte expansão econômica com o crescimento da indústria têxtil-vestuário e com o surgimento e a consolidação de outras atividades industriais, como metal-mecânico, fumo e alimentos. ${ }^{31}$

Com a entrada tardiamente em operação do trecho Blumenau a Itajaí da EFSC somente em 1954, a Seção Fluvial foi desativada e os materiais flutuantes foram abandonados ao longo das margens do Rio Itajaí-Açu.

O estado catarinense assumir os déficits da Seção Fluvial não era uma política isolada no país naquela época. Na verdade, o sistema de transporte brasileiro estatal, pautado na navegação (fluvial, marítima, com destaque para a 
Companhia de Navegação Lloyd Brasileiro) e nas ferrovias, era quase todo deficitário. Porém, ambos eram necessários para o processo de integração do mercado nacional dentro de projeto de industrialização amplamente financiada pelo estado. A opção pelas rodovias pós-1940, era uma forma de o estado transferir a responsabilidade do transporte de mercadorias e pessoas para a iniciativa privada. As vias de comunicação seriam construídas com recursos públicos, mas os meios de transportes e as empresas seriam privadas.

\section{CONSIDERAÇÕES FINAIS}

Analisando a história econômica dos transportes no vale do Itajaí, Santa Catarina, podemos encontrar elementos de uma totalidade do movimento de longa duração da política de transportes no Brasil. No Brasil, entre 1840 a 1880, foi dado ênfase ao transporte fluvial e marítimo a vapor. Os rios são estradas que andam, já dizia no século XVII o engenheiro Paschal, bastava melhor aproveitá-los para integrar regiões e servir de via de comunicação para transportar pessoas e mercadoria. Segundo Moraes, as grandes bacias brasileiras possibilitavam uma integração nacional, seria necessário "fazer apenas pequenos melhoramentos" ${ }^{32}$ Como não foi possível realizar a integração do mercado interno, pelos menos durante o século XIX, parte dos rios navegáveis brasileiros serviu como importante elo entre várias localidades e regiões. Neste período surgiram no Brasil várias companhias de navegação, para as quais o governo dava como garantia juros de $8 \%$ sobre o capital empregado, subvenção estatal e regalia de paquete. Neste bojo é que surge a Companhia de Navegação Fluvial a Vapor Itajahy-Blumenau.

No final do Império inauguramos uma nova era dos transportes no Brasil, a era ferroviária que predominou como política de transporte entre 1880 e 1940 . O complexo cafeeiro comandava a acumulação no setor ferroviário brasileiro, seguido de outras regiões que faziam parte dos complexos agro-mercantis exportadores, que ligava às regiões produtoras aos portos marítimos. A Estrada de Ferro Santa Catarina é inaugurada no auge da expansão ferroviária brasileira e parte do prolongamento é realizado nos anos de 1920 e 1930. A ligação ferroviária entre Blumenau e Itajaí levou à desativação da Seção Fluvial da EFSC. A ferrovia suplantou a navegação sem uma modernização nas estruturas da navegação. O trem substituiu o navio.

Entre 1940 e 1980, predominou no Brasil outra política de transporte, a rodoviária. Foram construídas e pavimentas longas rodovias que cortavam o país em todos os sentidos. Com a pavimentação da BR-470, que fazia o mesmo percurso da EFSC, não fazia mais sentido manter um ferrovia deficitária. A rodovia suplantou a ferrovia sem uma modernização nas estruturas das ferrovias. O caminhão substituiu o trem. 
174 REVISTA ESBOÇOS Volume 16, № 21, pp. 159-180 - UFSC

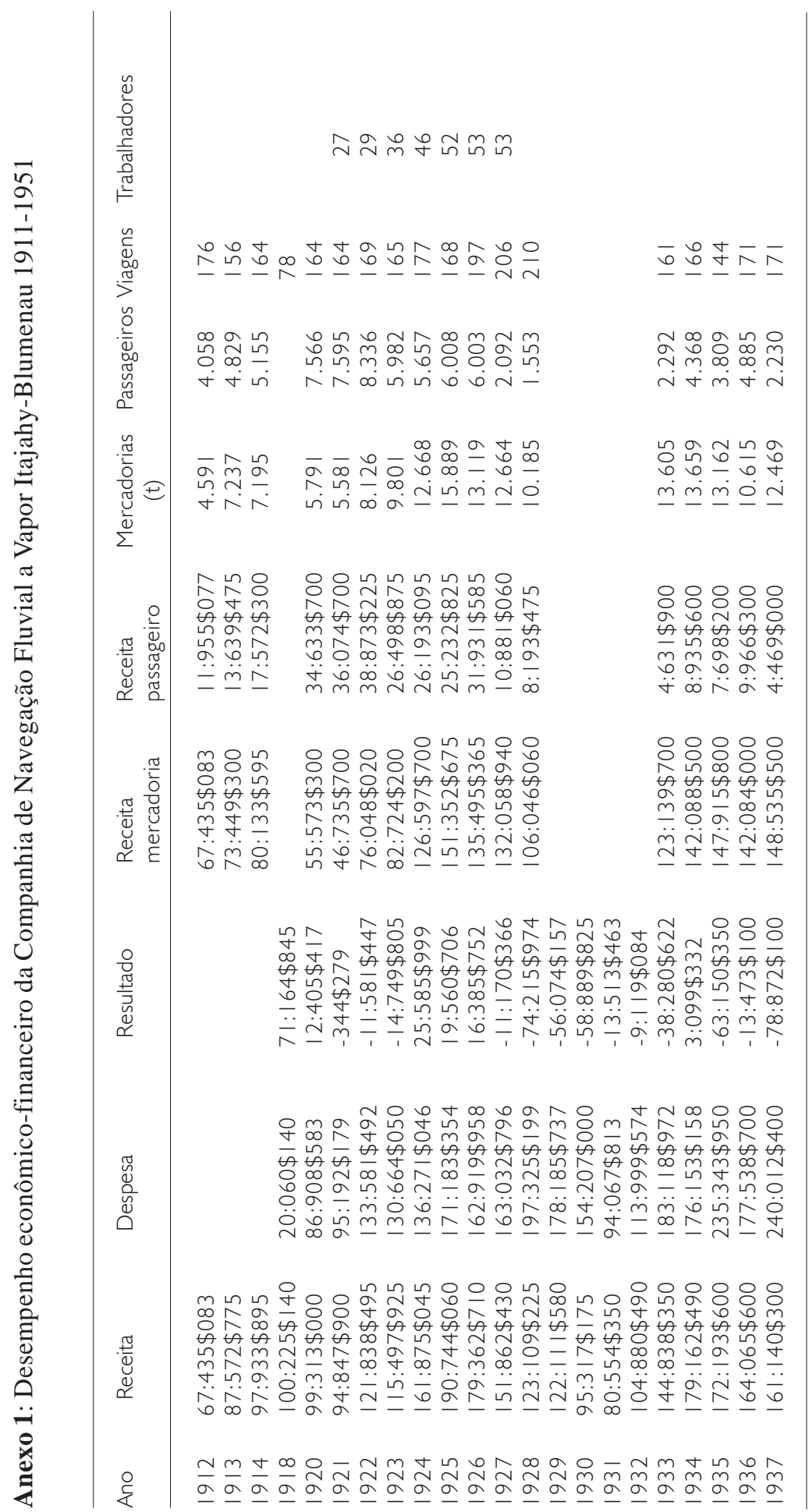




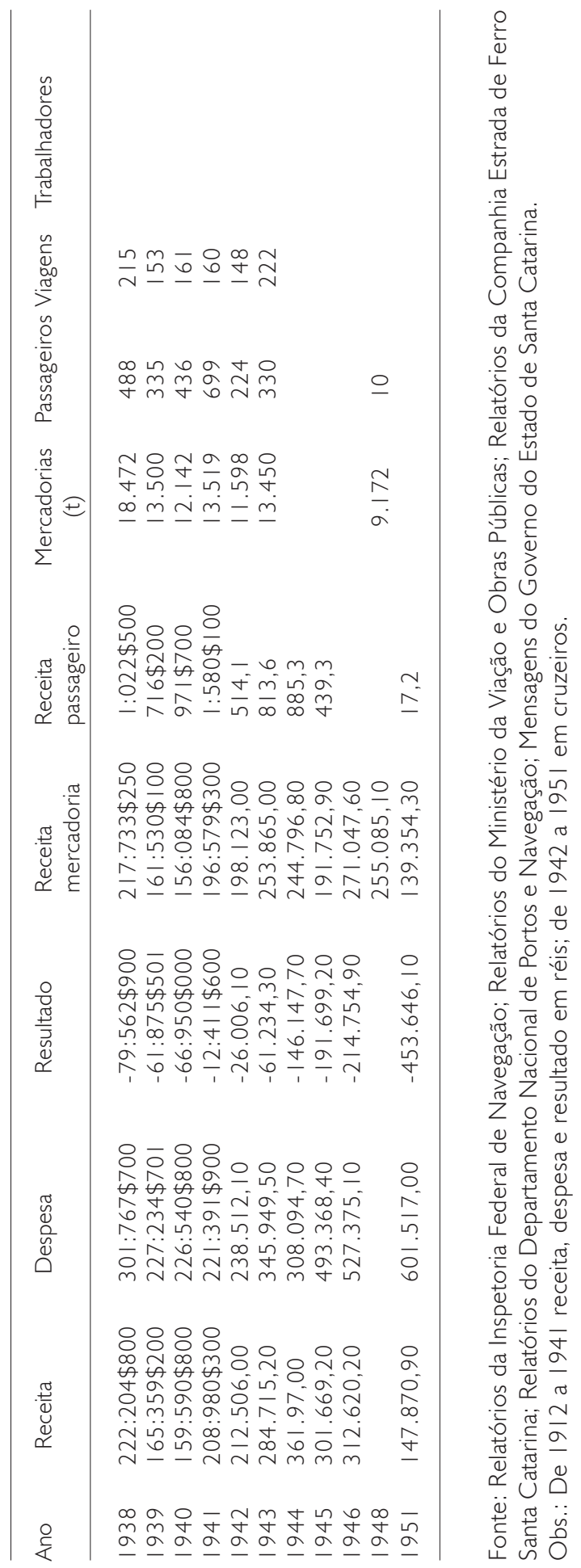




\section{LISTA DE FONTES:}

\section{Coleção de Leis}

BRASIL. Coleção de Leis do Império do Brasil de 1828. Rio de Janeiro: Tipografia Nacional, 1878. Disponível em: http://www.senado.gov.br Acesso em: 05 julho 2006.

. Coleção de Leis do Império do Brasil de 1833. Rio de Janeiro: Tipografia Nacional, 1872. Disponível em: http://www.senado.gov.br Acesso em: 05 julho 2006.

. Coleção das Leis do Império do Brasil de 1851. Rio de Janeiro: Tipografia Nacional, 1852. Disponível em: http://www.senado.gov.br Acesso em: 05 julho 2006.

. Coleção das Leis do Império do Brasil de 1874. Rio de Janeiro: Tipografia Nacional, 1875. Disponível em: http://www.senado.gov.br Acesso em: 05 julho 2006.

. Coleção das Leis do Império do Brasil de 1876. Rio de Janeiro: Tipografia Nacional, 1877 Disponível em: http://www.senado.gov.br Acesso em: 05 julho 2006.

Coleção das Leis do Império do Brasil de 1878. Rio de Janeiro: Tipografia Nacional, 1879. Disponível em: http://www.senado.gov.br Acesso em: 05 julho 2006.

Coleção das Leis do Império do Brasil de 1879. Rio de Janeiro: Tipografia Nacional, 1880. Disponível em: http://www.senado.gov.br Acesso em: 05 julho 2006.

. Decreto 13.539 de 9 de abril de 1919. Brasília: Senado Federal. Disponível em: http://www.senado.gov.br Acesso em: 05 julho 2006.

. Decreto 15.152 de 2 de dezembro de 1921. Brasília: Senado Federal. Disponível em: http://www.senado.gov.br Acesso em: 05 julho 2006. SANTA CATARINA. Coleção das Leis da Província de Santa Catarina de 1872. Desterro: Assembléia Provincial, 1872.

\section{Relatórios e Mensagens}

BRASIL. Relatório apresentado ao Presidente da República Arthur da Silva Bernardes pelo Ministro da Viação e Obras Públicas Francisco Sá no ano de 1923. Rio de Janeiro: Imprensa Nacional, 1924. Disponível em: http:// wwwcrl.uchicago.edu. Acesso em: 04 out. 2004.

Relatório apresentado ao Presidente da República dos Estados Unidos do Brasil Arthur da Silva Bernardes pelo Ministro da Viação e Obras Públicas Francisco de Sá no ano de 1925. Rio de Janeiro: Imprensa Nacional, 1928. Disponível em: http://wwwcrl.uchicago.edu. Acesso em: 04 out. 2004. 
ESTRADA DE FERRO SANTA CATARINA. Relatório apresentado ao Ministro da Viação e Obras Públicas pelo Diretor Oscar Barcellos. Blumenau, 1918. . Relatório apresentado ao Ministro da Viação e Obras Públicas pelo Diretor Oscar Barcellos. Blumenau, 1919.

. Relatório apresentado ao Governador de Santa Catarina pelo Diretor José Palhano de Jesus no ano de 1921. Blumenau: Tipografia Baumgarten, 1921.

. Relatório apresentado ao Governador de Santa Catarina pelo Diretor Joaquim José de Souza Breves Filho no ano de 1922. Blumenau: Tipografia Baumgarten, 1922.

. Relatório apresentado ao Governador de Santa Catarina pelo Diretor Joaquim José de Souza Breves Filho no ano de 1924. Blumenau: G. A. Koehler, 1924.

- Relatório apresentado ao Governador de Santa Catarina pelo Diretor Joaquim José de Souza Breves Filho no ano de 1926. Blumenau: G. A. Koehler, 1926.

. Relatório apresentado ao Governador de Santa Catarina pelo Diretor Joaquim José de Souza Breves Filho no ano de 1927. Blumenau: Tipografia Carl Wahle, 1927.

. Relatório apresentado ao Governador de Santa Catarina pelo Diretor Joaquim José de Souza Breves Filho no ano de 1928. Blumenau: Tipografia Carl Wahle, 1928.

. Relatório sobre a situação econômico-financeira e outros assuntos anexos de abril de 1936. Blumenau, 1936.

. Relatório sobre a situação econômico-financeira e outras notas agosto de 1937. Blumenau, 1937. - Memorial apresentado ao Interventor do Estado pelo Diretor Humberto Paranhos Pederneiras sobre a construção do trecho BlumenauGaspar. Blumenau, 1938.

- Relatório apresentado ao Interventor do Estado pelo Diretor

Francisco de Abreu e Lima Júnior do $1^{\circ}$ semestre de 1937. Blumenau, 1937. . Relatório apresentado ao Interventor do Estado pelo Diretor Humberto Paranhos Pederneiras do ano de 1941. Blumenau, 1942. . Relatório apresentado ao Interventor do Estado pelo Diretor

Humberto Paranhos Pederneiras do ano de 1942. Blumenau, 1943. . Relatório apresentado ao Interventor do Estado pelo Diretor Humberto Paranhos Pederneiras do ano de 1943. Blumenau, 1944. . Relatório apresentado ao Interventor do Estado pelo Diretor Humberto Paranhos Pederneiras do ano de 1944. Blumenau, 1945. 
. Relatório apresentado ao Governador do Estado pelo Diretor Humberto Paranhos Pederneiras do ano de 1945. Blumenau, 1946.

. Relatório apresentado ao Governador do Estado pelo Diretor Antônio Victorino Ávila Filho do ano de 1946. Blumenau, 1947. . Relatório da Estrada de Ferro Santa Catarina de 1948. Blumenau, 1948.

Blumenau, 1949.

. Relato do exercício de 1949 e dados estatísticos anexos. . Relatório referente ao ano de 1951. Blumenau, 1951.

MINISTÉRIO DA VIAÇÃO E OBRAS PÚBLICAS. Relatório da Inspetoria Geral de Navegação apresentado pelo inspetor Julio Delamare Koeler. Rio de Janeiro: Imprensa Nacional, 1911.

. Relatório da Inspetoria Federal de Navegação apresentado pelo inspetor Frederico Cezar Burlamaqui no ano de 1920. Rio de Janeiro: Imprensa Nacional, 1922.

Relatório da Inspetoria Federal de Navegação apresentado

pelo inspetor Ademar de Mello Franco no ano de 1926. Rio de Janeiro: Imprensa Nacional, 1930.

. Relatório dos serviços executados pelo Departamento Nacional de Portos e Navegação durante o ano de 1934 apresentado pelo Diretor Frederico Cezar Burlamaqui. Rio de Janeiro: Oficina dos Correios e Telégrafos, 1936.

- Relatório dos serviços executados pelo Departamento Nacional de Portos e Navegação durante o ano de 1935 apresentado pelo Diretor Frederico Cezar Burlamaqui. Rio de Janeiro: Oficina dos Correios e Telégrafos, 1936.

. Relatório dos serviços executados pelo Departamento Nacional de Portos e Navegação durante o ano de 1936 apresentado pelo Diretor Frederico Cezar Burlamaqui. Rio de Janeiro: Oficina dos Correios e Telégrafos, 1937.

Relatório dos serviços executados pelo Departamento Nacional de Portos e Navegação em 1937 apresentado pelo Diretor Frederico Cezar Burlamaqui. Rio de Janeiro: Gráfica do DNPN, 1938.

- Relatório dos serviços executados pelo Departamento Nacional de Portos e Navegação em 1938 apresentado pelo Diretor Frederico Cezar Burlamaqui. Rio de Janeiro: Gráfica do DNPN, 1939.

. Relatório dos serviços executados no ano de 1939 pelo Departamento Nacional de Portos e Navegação apresentado pelo Diretor Frederico Cezar Burlamaqui. Rio de Janeiro: Imprensa Nacional, 1940. 
. Relatório dos serviços executados no ano de 1940 pelo Departamento Nacional de Portos e Navegação apresentado pelo Diretor Frederico Cezar Burlamaqui. Rio de Janeiro: Imprensa Nacional, 1941. Relatório dos serviços executados no ano de 1941 pelo Departamento Nacional de Portos e Navegação apresentado pelo Diretor Frederico Cezar Burlamaqui. Rio de Janeiro: Imprensa Nacional, 1943. Relatório dos serviços executados no ano de 1942 pelo Departamento Nacional de Portos e Navegação apresentado pelo Diretor Frederico Cezar Burlamaqui. Rio de Janeiro: Imprensa Nacional, 1944.

PARANÁ. Relatório do Presidente Affonso Alves Camargo apresentada ao Congresso legislativo do Estado em $1^{\circ}$ de fevereiro de 1918. Curitiba: Tipografia da República, 1918.

. Relatório do Presidente Affonso Alves Camargo apresentada ao Congresso legislativo do Estado em $1^{\circ}$ de fevereiro de 1920. Curitiba: Tipografia da República, 1920.

SANTA CATARINA. Mensagem apresentada pelo Vice-Presidente da Província de Santa Catarina à Assembléia Legislativa em 7 de agosto de 1893. Desterro: Gabinete Sul-Americano, 1893.

. Mensagem apresentada pelo Interventor Nereu Ramos em 1938.

Florianópolis: Imprensa Oficial, 1938.

\section{Jornais}

BLUMENAUER ZEITUNG, 30 de abril de 1877 (Disponível Arquivo Histórico Municipal de Blumenau).

BLUMENAUER ZEITUNG, julho de 1900 (Disponível Arquivo Histórico Municipal de Blumenau).

\section{NOTAS}

${ }^{2}$ Cf. PIAZZA, Walter F. A colonização de Santa Catarina. Florianópolis: Lunardelli, 1994.

${ }^{3}$ Cf. GOULARTI FILHO, Alcides. "Sistema portuário catarinense: a construção dos portos de São Francisco do Sul, Itajaí e Imbituba". In: Anais das Primeiras Jornadas de Economia Regional Comparada. Porto Alegre: PUCRS/FEE, 2005.

${ }^{4}$ PRADO JÚNIOR, Caio. Formação do Brasil contemporâneo. São Paulo: Brasiliense, 1996.

${ }^{5}$ Cf. MORAES, Eduardo José de. Navegação interior do Brasil. Rio de Janeiro: Tipografia Montenegro, 1894. (Primeira edição de 1869), p. 50.

${ }^{6}$ Coleção das Leis do Império do Brasil de 1878. Rio de Janeiro: Tipografia Nacional, I879, p. 24. Disponível em: http://www.senado.gov.br Acesso em: 05 julho 2006. 
${ }^{7}$ Coleção de Leis do Império do Brasil de 1833. Rio de Janeiro: Tipografia Nacional, I872, p. III. Disponível em: http://www.senado.gov.br. Acesso em: 05 julho 2006.

${ }^{8}$ Cf. Coleção das Leis do Império do Brasil de 185/. Rio de Janeiro: Tipografia Nacional, I852. Disponível em: http://www.senado.gov.br Acesso em: 05 julho 2006.

9 FERREIRA NETO, Francisco. 150 anos de transportes no Brasil. Rio de Janeiro: CEDOP/MT, 1974.

10 COIMBRA, Créso. Visão histórica e análise conceitual dos transportes no Brasil. Rio de Janeiro: CEDOP/MT, 1974.

"MARTINS, Alfredo Romário. "Caminhos históricos do Paraná." In: REDE DE VIAÇÃO PARANÁ SANTA CATARINA. Cinqüentenário da Estrada de Ferro do Paraná 1885-1935. Curitiba, 1935.

${ }^{12}$ AGAPITO, Maria Zolene Dias. Estrada Dona Francisca. Joinville: FERJ/UFPR, 1989. (Monografia de especialização).

13 PARANÁ. Relatório do Presidente Affonso Alves Camargo apresentada ao Congresso legislativo do Estado em $1^{\circ}$ de fevereiro de 1918. Curitiba: Tipografia da República, 1918.

Relatório do Presidente Affonso Alves Camargo apresentada ao Congresso Legislativo do Estado em ${ }^{\circ}$ de fevereiro de 1920. Curitiba: Tipografia da República, 1920.

14 REISEMBERG, Alvir. "Navegação a vapor nos rios Negro e Iguaçu". In: Cadernos do PMDB do Paraná. Navegar é preciso. Curitiba, ano I, n. 2, 1984.

15 KROETZ, Lando Rogério. Estradas de ferro do Paraná 1880-1940. São Paulo: FFLCH/USP, 1985. (Tese de doutorado).

${ }^{16}$ GOULARTI FILHO, Alcides. Formação econômica de Santa Catarina. Florianópolis: Cidade Futura, 2002.

17 BLUMENAU EM CADERNOS. Navegação pelo rio. Blumenau, tomo IX, n 6, junho de 1969. KORMANN, Edith. Blumenau: arte, cultura e as histórias de sua gente 1850-1985. Blumenau: Editora do Autor, 1995.

${ }^{18}$ Coleção das Leis da Província de Santa Catarina de 1872. Desterro: Assembléia Provincial, 1872.

${ }^{19}$ Coleção das Leis do Império do Brasil de 1874. Rio de Janeiro: Tipografia Nacional, I 875. Disponível em: http://www.senado.gov.br. Acesso em: 05 julho 2006.

${ }^{20}$ Coleção das Leis do Império do Brasil de 1876. Rio de Janeiro: Tipografia Nacional, 1877. Disponível em: http://www.senado.gov.br. Acesso em: 05 julho 2006.

21 BLUMENAUER ZEITUNG, 30 de abril de 1877.

${ }^{22}$ Coleção das Leis do Império do Brasil de 1878. Rio de Janeiro: Tipografia Nacional, 1879. Disponível em: http://www.senado.gov.br. Acesso em: 05 julho 2006.

${ }^{23}$ BLUMENAUER ZEITUNG, julho de 1900.

${ }^{24}$ KORMANN, cit. 1985.

25 ESTRADA DE FERRO SANTA CATARINA, Relatório apresentado ao Governador de Santa Catarina pelo Diretor José Palhano de Jesus no ano de 1921. Blumenau: Tipografia Baumgarten, 1921.

${ }^{26}$ ESTRADA DE FERRO SANTA CATARINA, Relatório apresentado ao Governador de Santa Catarina pelo Diretor Joaquim José de Souza Breves Filho no ano de 1927. Blumenau: Tipografia Carl Wahle, 1927, p. 9- 10.

${ }^{27}$ ESTRADA DE FERRO SANTA CATARINA, Relatório apresentado ao Governador de Santa Catarina pelo Diretor Joaquim José de Souza Breves Filho no ano de 1928. Blumenau: Tipografia Carl Wahle, 1928, p. 7.

${ }^{28}$ ESTRADA DE FERRO SANTA CATARINA, Relatório sobre a situação econômico-financeira e outros assuntos anexos de abril de 1936. Blumenau, 1936.

${ }^{29}$ Idem, Ibidem, p. 8.

30 ESTRADA DE FERRO SANTA CATARINA, Memorial apresentado ao Interventor do Estado pelo Diretor Humberto Paranhos Pederneiras sobre a construção do trecho Blumenau-Gaspar. Blumenau, 1938. 1938, p. 104.

3) GOULARTI FILHO, op. cit., 2002.

${ }^{32}$ Cf. MORAES, cit. 